\title{
¿Representa el turismo culinario una oportunidad para valorizar el patrimonio agroalimentario? El caso del centro histórico de Quito
}

\section{Does culinary tourism represent an opportunity to enhance the agri-food heritage? The case of the historical center of Quito}

\author{
Maria Elena Sosa-Sosa \\ mesosa@uce.edu.ec @ https://orcid.org/0000-0002-6759-841X \\ Facultad de Agronomía. Universidad Central del Ecuador. Ciudadela Universitaria, \\ Calle Jerónimo Leyton SN y Gilberto Gatto Sobral. Quito- Ecuador. C.P. 170809. \\ Humberto Thomé-Ortiz \\ hthomeo@uaemex.mx@ https://orcid.org/0000-0002-6714-3490 \\ Instituto de Ciencias Agropecuarias y Rurales. Universidad Autónoma del Estado de México. \\ El Cerrillo, Piedras Blancas, Toluca, Estado de México, México. C. P. 50090.
}

\section{INFO ARTÍCULO}

Recibido: 16-5-2020

Revisado: 14-6-2020

Aceptado: 17-6-2020

\section{PALABRAS CLAVE}

Turismo agroalimentario

Cocina tradicional

Desarrollo local

Cultura alimentaria

\section{KEYWORDS}

Culinary tourism

Traditional cuisine

Local development

Local commerce

Food culture

\section{RESUMEN}

Este trabajo tiene como objetivo identificar la manera en que los restaurantes emblemáticos se relacionan con el patrimonio agroalimentario de Quito, a partir de su vinculación con los pequeños productores locales. Con base en un estudio de caso, se construyó una reflexión en torno a observaciones empíricas y fuentes secundarias. Los resultados muestran que los alimentos ofrecidos, en su mayoría, suelen adquirirse con grandes proveedores de zonas remotas, desvinculándose del sector agroalimentario local. Se concluye que el turismo puede jugar un papel importante en la distribución equitativa del ingreso entre los diversos actores económicos del territorio y en la continuidad de los sistemas agroalimentarios locales, para ello es fundamental la articulación entre los sectores turístico y agropecuario, a partir de la lógica del comercio de proximidad.

\begin{abstract}
The aim of this paper is to identify the manner in which emblematic restaurants are related with the agri-food heritage of Quito from the connection with small local producers. Based on a case study, an analysis was made around empirical observations and secondary sources. The results show that the food offered tend to be acquired from large suppliers of remote areas, decoupling from the local agricultural sector. It is concluded that tourism can play an important role in the equal distribution of income among the diverse economic participants of the sector and in the continuity of the local agri-food systems. For this, the coordination between the tourist and agri-food industries is fundamental, starting with the logic of local commerce.
\end{abstract}




\section{INTRODUCCIÓN}

El turismo agroalimentario es una modalidad turística que se centra en el aprovechamiento recreativo de los sistemas agroalimentarios locales, a través de la interpretación turística de la cadena de valor, que incluye su trayectoria de la tierra al plato (De Jesús-Contreras, Thomé-Ortiz, Espinoza-Ortega y Vizcarra-Bordi et al., 2017). Algunos trabajos han documentado la importancia del turismo en la puesta en valor, económico y cultural, de los recursos agroalimentarios anclados al territorio (Fritscher, 2002; Espeteix, 2004). Además, se debe considerar que los alimentos locales ofrecidos por redes agroalimentarias alternativas pueden representar una alternativa para los actores rurales que estén dispuestos a establecer una relación más estrecha con el sector turístico (Forney, 2016).

La piedra angular de las propuestas turísticas basadas en alimentos es el valor patrimonial de los mismos, el cual sintetiza conocimientos, técnicas y significados relacionados con la comida desde una perspectiva histórica (Torres, 2004). Dicho patrimonio también adquiere una expresión espacial, al convertir algunos alimentos en emblemas del territorio, que suelen estar anclados a espacios con profundidad histórica como pueden ser los centros históricos de las ciudades y sus establecimientos alimentarios.

Algunos trabajos destacan la importancia del patrimonio gastronómico como elemento focal de atracción turística en las ciudades (Millán Vázquez de la Torre, Hernández Rojas y Navajas Romero, 2016; Hernández-Mogollon, Di-Clemente y López Guzmán, 2015; Aguirregoitia Martínez y Fernández Poyatos, 2017). En el caso de la Quebrada de Humahuaca y Puna en el norte de Argentina (Troncoso y Arseno, 2019) y en poblaciones de Turrrialba en Costa Rica (Blanco, 2012), también se han identificado casos donde los alimentos emblemáticos funcionan como elementos de atracción turística como en el caso de la barbacoa de cordero en la ciudad de Texcoco, México (Thomé-Ortiz, 2018).

La actividad turística puede ayudar a elevar la cocina tradicional al estatus de bien patrimonial cultural, lo cual genera expectativas sociales, políticas y económicas sobre la valorización de los recursos agroalimentarios (Blas-Yánez, Thomé-Ortiz, Espinosa-Ortega, y Vizcarra-Bordi, 2018). Esta relación entre turismo y alimentos emblemáticos es lo que se analiza en la presente investigación, toda vez que los alimentos tradicionales son marcadores de la identidad territorial (Ministerio de Cultura y Patrimonio del Ecuador, 2016) que pueden ser susceptibles de convertirse en atractivos turísticos.

En la medida en que un recurso agroalimentario presente un fuerte anclaje territorial (Espeitx, 2004; Barrera y Bringas, 2009) y se oponga a la estandarización del sistema alimentario global (Bowen y Mutersbaugh, 2013) este puede apelar a diferentes intereses de consumo con motivaciones sociales, culturales y/o ambientales (Boucher, 2012), siendo el turismo un mecanismo eficaz para acercar los alimentos emblemáticos con los consumidores, más allá de su esfera doméstica (Thomé-Ortiz, 2015). Sin embargo, no en todos los casos se observa que estos beneficios del turismo culinario se extiendan hacia las periferias rurales de los centros turísticos.

Ciertamente, el turismo no sólo se relaciona con alimentos desarticulados y fuera de contexto, sino que establece puentes con las culturas alimentarias que refieren al conjunto de representaciones, creencias, conocimientos y prácticas que están asociadas a la alimentación y que son compartidas por los individuos de una cultura dada (Contreras y Gracia, 2005). Es decir, que la reinterpretación turística de los alimentos se construye alrededor de una sinergia entre recursos naturales, culturales, capital social, infraestructura y dinámicas de mercado que determinan su nivel de éxito (Mascarenhas y Gândara, 2010).

El creciente interés turístico por las cocinas tradicionales responde a la tendencia de incluir diversas expresiones de la cultura inmaterial en la esfera de lo patrimonializable, mediante procesos de institucionalización de las identidades culturales (Medina, 2017). Sin embargo, ello presenta un dilema al referirse a actores concretos, normalmente hegemónicos, que se apropian de bienes comunes, en este caso el patrimonio agroalimentario. A ello hay que agregar el hecho de que los patrones alimentarios contemporáneos han generado distanciamiento y desvinculación entre lo que se sirve en la mesa y su origen en la tierra, aspecto que conlleva a una falta de reconocimiento cultural y económico a los productores de alimentos, con lo que uno de los grandes supuestos (el desarrollo rural) que justifican la turistificación de diversos artefactos culturales estaría en entredicho (Fusté-Forné, 2015; Fusté-Forné, 2016). 
Para ello resulta fundamental vincular las modalidades de turismo gastronómico y culinario con el patrimonio agroalimentario local, analizando la capacidad de este para atraer visitantes (Espeitx, 2004). Desde nuestra perspectiva, es fundamental que, más allá de la esfera gastronómica, el turismo basado en alimentos se construya a partir de la recuperación de la cadena de valor agroalimentaria, implicando aspectos ambientales, económicos, sociales y culturales (Leal Londoño, 2015). Con ello se estaría generando un verdadero proceso de transformación socioeconómica en el territorio.

Para Hall \& Mitchell (2001) el turismo culinario incluye visitas a productores de alimentos, festivales y restaurantes, siendo la comida el principal motivo de desplazamiento de los turistas. Este tipo de turismo permite establecer vínculos entre los alimentos y el turismo, fortaleciendo la identidad y la cultura local, contribuyendo a proteger el patrimonio agroalimentario para las siguientes generaciones (Hall, Mitchell, Sharples, Maciones \& Combourne, 2003). En el caso de este estudio los establecimientos de alimentos del Centro Histórico de Quito (C.H.Q) muestran una continuidad histórica tanto de los propietarios como de los comensales. De acuerdo con Kivela y Crotts (2006) el turismo culinario se ancla en las cocinas tradicionales relacionadas con lugares específicos. Siendo esta vinculación entre turismo y alimentos una sinergia entre la agricultura que proporciona el alimento, la cultura que aporta el entorno sociohistórico, y el turismo que genera infraestructuras y servicios para la implementación de experiencias alimentarias (Du Rand \& Heath, 2006).

El desarrollo del turismo de alimentos emblemáticos debe incluir a los productos y a los productores de la región (Alonso \& Yiliu, 2011). Entonces, una perspectiva turística que verdaderamente busque reivindicar a los alimentos locales debería basarse en el comercio de proximidad, como una alternativa para adquirir, a un precio justo, los insumos provenientes de agricultores y ganaderos de la zona (Leal Londoño, 2015). Se trata de que los establecimientos de alimentos emblemáticos se vinculen a cadenas agroalimentarias de proximidad, donde los productos son vendidos a través de salidas locales en la región (Goodman, 2004). Además, este factor puede añadir valor a la oferta culinaria porque otorga confianza, calidad y un sentido de identidad en el consumidor.

El consumo turístico de alimentos locales se considera sostenible debido a que apoya la economía local (Jiménez-Beltrán, López-Guzmán, González Santa Cruz, 2016) y disminuye la huella de carbono por la reducción de las distancias de transporte (Yurtseven, 2011). Entonces, el gasto turístico puede favorecer la economía local y específicamente contribuir al mantenimiento de los sistemas agroalimentarios locales (Du Rand, Heath \& Alberts, 2003). Es por este motivo que a pesar de que nuestro objeto de estudio es del orden culinario, nuestra investigación se enfoca a partir de la lógica del turismo agroalimentario, es decir que recupera los objetos de patrimonialización turística de la tierra al plato (Thomé-Ortiz, Vizcarra Bordi, Chávez-Mejía y Herrera-Tapia, 2015).

Este trabajo enfoca el papel que la valorización turística del patrimonio agroalimentario puede jugar en la dinamización económica del territorio, a partir de las posibles articulaciones entre alimentos emblemáticos y turismo, como elementos de atracción turística (Bessière, Poulain \& Tibère, 2013). El objetivo fue identificar la manera en que los restaurantes emblemáticos del Centro Histórico de Quito se relacionan con el patrimonio agroalimentario local, a partir de su vinculación con los pequeños productores de las periferias rurales. Con ello se busca desarrollar una perspectiva crítica sobre los procesos de patrimonialización de las cocinas tradicionales, indagando sobre la contribución del turismo a la sostenibilidad de los productores locales que están involucrados en la producción primaria del patrimonio agroalimentario.

\section{METODOLOGÍA}

Entre abril de 2017 y enero de 2020 se llevó a cabo un estudio de caso (Stake, 2000) sobre la relación entre la producción agroalimentaria local y los establecimientos de alimentos emblemáticos del Centro Histórico de Quito. Para ello se desarrolló un estudio descriptivo que integró variables cualitativas y cuantitativas, desde un enfoque sociológico que tuvo como ejes articuladores una oferta turística diferenciada y el desarrollo rural vinculado con la producción agropecuaria. 
El presente trabajo comprendió dos fases: una documental y otra de campo. Para la primera fase se realizó un análisis teórico sobre la relación entre patrimonio agroalimentario y turismo, a partir de la revisión de fuentes secundarias. La búsqueda de información bibliográfica se realizó en las bases de datos Elsevier y REDALyC, a partir de palabras clave que incluían los conceptos de cultura alimentaria, alimentos emblemáticos, turismo agroalimentario, turismo gastronómico, turismo culinario y la relación de estos con el desarrollo local. Se buscó que las fuentes seleccionadas procedieran de revistas indexadas y arbitradas, así como que los autores fueran referentes en el campo de estudios mediante sus indicadores de citación verificada en sus perfiles de Google Scholar, Scopus y Web of Science.

Para el trabajo de campo fueron aplicadas 16 entrevistas semiestructuradas a los propietarios, administradores y/o encargados de los establecimientos de alimentos emblemáticos del Centro Histórico de Quito. Las temáticas desarrolladas fueron: las características de los establecimientos, su historia, la estructura de su oferta gastronómica, sus mercados, sus proveedores y su relación con el territorio. Se aplicó una entrevista por cada establecimiento (anexo 1), cubriendo con este número la totalidad de aquellos catalogados como emblemáticos en el C.H.Q. como se indica en la tabla 1.

La selección de dichos lugares se realizó a partir del catálogo de establecimientos de alimentos emblemáticos desarrollado por el Instituto Nacional de Patrimonio Cultural (INPC) entre los años 2015 y 2017 en el C.H.Q., mismo que fue realizado por un grupo de expertos en gastronomía, turismo y patrimonio alimentario, considerando los siguientes aspectos: antigüedad, continuidad generacional de los propietarios y consumidores, nicho de mercado específico, valor histórico de los inmuebles, carácter familiar de los establecimientos y oferta de platos tradicionales. La categorización de los establecimientos alimentarios dada por el Ministerio de Turismo se hizo con base en tres puntos fundamentales: buenas prácticas de manufactura, servicios e infraestructura (MINTUR, 2018b).

También se aplicaron 3 entrevistas semiestructuradas a especialistas del Instituto Nacional de Investigaciones Agropecuarias (INIAP) donde se abordaron aspectos referentes a la producción agroalimentaria local y su relación con la cocina tradicional del C.H.Q. Se realizaron 3 entrevistas semiestructuradas a productores de maíz, papa y trigo, en donde se abordaron temas como la producción, comercialización y la articulación con los servicios de restauración. Por otra parte, se entrevistó a un funcionario del Ministerio de Turismo para conocer el trabajo gubernamental respecto al turismo culinario. También se entrevistó a la encargada del Programa de Agricultura Urbana y Participativa del Municipio de Quito (AGRUPAR) donde se tomaron en cuenta aspectos como: comercio justo, productos alimentarios de calidad y cadenas agroalimentarias alternativas.

La muestra de los entrevistados se determinó a partir de la técnica no probabilística de bola de nieve que consiste en que los primeros individuos seleccionados conducen a otros de forma exponencial (Espinoza Tames, Hernández Sinencio, López Guzmán y Lozano Esparsa, 2018). La validación de la muestra se realizó por criterio de saturación que implica continuar indagando hasta el momento en el que no se encuentre nueva evidencia respecto a cada concepto desarrollado en las entrevistas (Goulding, 2009; Cresswell, 2007 y Esper, 2011). Por otra parte, se aplicó una encuesta a una muestra de 384 turistas nacionales que visitan el cantón Quito (anexo 2), con la intención de identificar los alimentos identitarios y tradicionales que para ellos eran representativos de la región.

Ciertamente, la información derivada de este estudio tiene valor en términos de su aportación a la construcción del conocimiento en tanto estudio de caso (Stake, 2000). Es decir que a pesar de que la muestra de entrevistados es relativamente pequeña, permite recuperar las experiencias y perspectivas de un grupo que pertenece a un pequeño colectivo con presencia global: el de los oferentes de alimentos tradicionales en los centros históricos de destinos turísticos relevantes. Por tanto, este trabajo es una primera aproximación para discutir la relación entre producción local y turismo culinario, a través del aura patrimonial que aporta la localización de estos espacios, siendo reservorios de la tradición con una excepcional afluencia turística. 
Tabla 1. Establecimientos emblemáticos del centro histórico de Quito.

\begin{tabular}{|c|c|c|c|c|}
\hline No. & Establecimiento & Fundación & Herencia intergeneracional & Clasificación \\
\hline 1 & Cafetería Bodega Meneses & 1981 & $2^{\text {da }}$ generación & $2^{\text {da }}$ categoría \\
\hline 2 & Cafetería El Buen Café Quito & 1950 & $2^{\text {da }}$ generación & $2^{\text {da }}$ categoría \\
\hline 3 & Cafetería El Pretil de Alicia & 1944 & $2^{\text {da }}$ generación & $2^{\text {da }}$ categoría \\
\hline 4 & Dulcería Cafetería: Colaciones Cruz Verde & 1915 & $4^{\text {ta }}$ generación & $2^{\text {da }}$ categoría \\
\hline 5 & Heladería-Restaurante San Agustín & 1858 & $6^{\text {ta }}$ generación & $2^{\text {da }}$ categoría \\
\hline 6 & Procesadora Café Águila de Oro & 1947 & $2^{\text {da }}$ generación & No clasificado \\
\hline 7 & Restaurante y Cafetería Modelo & 1950 & $2^{\text {da }} \cdot$ generación & $2^{\text {da }}$ categoría \\
\hline 8 & Restaurante Cafetería Mr. Meneses e hijos & 1979 & $2^{\text {da }}$ generación & 1era categoría \\
\hline 9 & Fonda Mama Miche & 1940 & $2^{\text {da }}$ generación & $2^{\text {da }}$ categoría \\
\hline 10 & Confitería artesanal Kukurucho del Maní & 1999 & $2^{\text {da }}$ generación & No clasificado \\
\hline 11 & Ponches Magolita & 1944 & 3era generación & No clasificado \\
\hline 12 & Restaurante Diosolopay & $\begin{array}{l}1620 \text { (Primera cafetería de la } \\
\text { Universidad de San Gregorio, } \\
\text { actualmente Universidad Central } \\
\text { del Ecuador). }\end{array}$ & $\begin{array}{l}\text { 1era generación (adquirida hace } 10 \\
\text { años por su actual propietario) }\end{array}$ & $1^{\text {era }}$ categoría \\
\hline 13 & Restaurante La Colmena & 1958 & $2^{\text {da }}$ generación & $2^{\text {da }}$ categoría \\
\hline 14 & Salón Don Lucho & 1969 & $1^{\text {era }}$ generación & 2da categoría \\
\hline 15 & Picantería Laurita & 1947 & $2^{\text {da }}$ generación & $2^{\text {da }}$ categoría $>$ \\
\hline 16 & Heladería y Cafetería Caribe & 1950 & $2^{\text {da }}$ generación & $2^{\text {da }}$ categoría \\
\hline
\end{tabular}

Fuente: Elaboración propia.

\subsection{Zona de estudio}

La Ciudad de Quito es la capital del Ecuador y de la provincia de Pichincha con 2.781.641 habitantes (INEC, 2020), se localiza 13 kilómetros al sur de la línea equinoccial, a 2.805 metros sobre el nivel del mar (Quito Turismo, 2011). Fue declarada por la UNESCO como “Patrimonio Cultural de la Humanidad" el 18 de septiembre de 1978 (Ministerio de Cultura y Patrimonio, 2013). Entre sus recursos más importantes se encuentra su centro histórico, que es considerado el más grande y mejor preservado de Latinoamérica, con una extensión de 320 hectáreas que albergan 130 edificaciones monumentales y 5.000 inmuebles de la época colonial (Quito Turismo, 2011). Además de su extenso patrimonio material, la ciudad tiene una amplia riqueza cultural que incluye una variada gastronomía tradicional (Ministerio de Cultura y Patrimonio, 2013).

Según el Ministerio de Turismo (MINTUR, 2018a), el cantón Quito presenta una concentración importante de turistas con relación a la demanda turística de la provincia, siendo el centro histórico de la ciudad, uno de los principales puntos visitados. La llegada de turistas extranjeros para el año 2018 correspondió a 540.767 turistas y 151.725 para turistas nacionales (Quito Turismo, 2020). De acuerdo con Quito Turismo (2019) la actividad turística más representativa en el cantón es "alimentos y bebidas" en un $64 \%$ y, específicamente, en el Centro Histórico de Quito representa el 79,2\%, más de las tres cuartas partes del servicio que se ofrece en este sector (MINTUR, 2020). Esto indica que hay una gran cantidad de establecimientos relacionados con la alimentación que generan impactos económicos sobre la población. De acuerdo con el INPC (2017), el C.H.Q. concentra el $56,9 \%$ de los establecimientos de comida emblemática designados como patrimonio (figura 1). 
El área urbana es sólo el $8 \%$ del cantón, sin embargo, agrupa un $68,4 \%$ de la población (Ramón, Alarcón, Guerrero y Vivero, 2018), con una marcada concentración de los recursos y las actividades económicas en el espacio urbano, lo cual produce asimetrías respecto a las oportunidades para el espacio rural. Por ello un aspecto central de este trabajo es plantear los posibles beneficios que actividades como el turismo pueden representar en los flujos económicos entre los ámbitos urbano y rural (Avila-Sánchez, 2005).

Particularmente, llama la atención la presencia de una oferta gastronómica emblemática en las zonas urbanas, basada en productos tradicionales y su aparente desvinculación con los productores de las zonas rurales. Por tal razón, se hace énfasis en aspectos referentes a la comercialización y a las características de los productos representativos del territorio (maíz, papa y trigo), con particular interés en las dinámicas territoriales de estos alimentos.

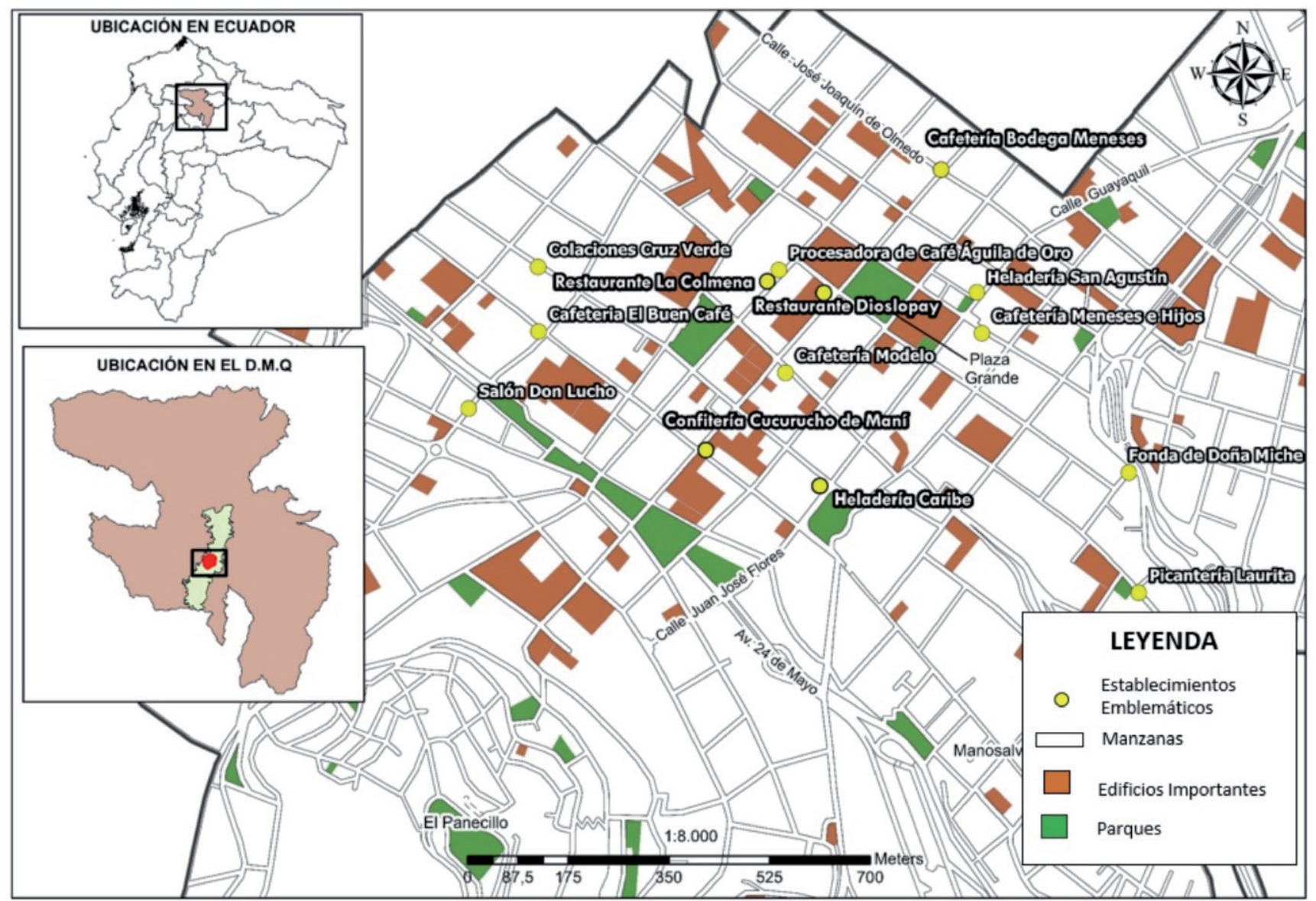

Figura 1. Establecimientos alimentarios emblemáticos en el centro histórico de Quito. Fuente: Elaboración propia.

\section{RESULTADOS Y DISCUSIÓN}

\subsection{Los productos agroalimentarios del cantón Quito}

Dentro de los productos más importantes que se cultivan en la provincia de Pichincha, está el maíz con un 4,8 \% (Ramón et al., 2018). Para el SIPA (Sistema de Información Pública Agropecuaria, 2018) el maíz es el quinto cultivo en orden de importancia de superficie sembrada, con 2.415 hectáreas destinadas a maíz suave que es el choclo (elote); y el maíz suave seco tiene el sexto lugar con 2.287 hectáreas. Si sumamos la superficie sembrada de maíz suave choclo y maíz suave seco es igual a 4.702 hectáreas, siendo el tercer cultivo en importancia dentro de la provincia. Sin embargo, la producción de maíz en estos últimos años ha 
disminuido notablemente, como nos manifiesta el técnico del INIAP especialista en maíz (entrevista, 16 de septiembre del 2019):

"En pocos lugares del cantón Quito se sigue sembrando maíz, más se produce en otras provincias, se ha dejado de producir en el Valle de los Chillos que era el granero de Quito, solo en Amaguaña y Píntag se sigue sembrando, en Tumbaco antes se producía, ahora no. En Calacalí, en Pululahua hay una producción importante de maíz y en San Antonio de Pichincha en menor medida. En San José de Minas también existe una producción, pero es para morochillo, alimento de las aves."

La papa es el segundo cultivo en cuanto a superficie plantada de la provincia de Pichincha contando con 5.709 hectáreas (SIPA, 2018). En 2014, se cultivó papa en 12 provincias del país, las provincias de mayor productividad (sobrepasan el promedio nacional), siendo Pichincha la segunda en importancia con 14,72 t/ha, después de Carchi con 22,43 t/ha, y otras provincias destacadas en este cultivo son Tungurahua (14,04 t/ha) y Chimborazo (13,80 t/ha) (Monteros, 2016). Ecuador registró, en 2014, 49.000 hectáreas cultivadas de papa, con un $90 \%$ de la cosecha destinada a la comercialización y un $10 \%$ al autoconsumo o para el cultivo del siguiente ciclo (Monteros, 2016).

La papa es uno de los cultivos tradicionales en Ecuador, en cuya producción se vincula a 82.000 productores en un total de 90 cantones (Monteros, 2016). Con relación a la distribución del cultivo de papa en el cantón Quito, cada vez hay menos lugares donde se siembra este cultivo como en Pifo, Puembo y muy poco en Tumbaco y Nono (entrevista a técnico especialista en papa, 16 de septiembre del 2019).

El trigo tiene una superficie plantada en la provincia de Pichincha de 573 ha (SIPA, 2018), siendo el cultivo onceavo en importancia. Sin embargo, los ecuatorianos son trigo-dependientes porque el $99 \%$ del trigo que se consume en Ecuador es importado, apenas el $1 \%$ es producido en el país. El trigo importado proviene de Rusia, Argentina, Canadá y Estados Unidos. Las provincias con mayor superficie de siembra son Bolívar, Imbabura, Chimborazo y Pichincha (entrevista a técnico del INIAP especialista en trigo, 16 de septiembre del 2019).

El $61 \%$ de los agricultores en la provincia de Pichincha son pequeños productores que tienen menos de una hectárea, mientras sólo el 5,7\% de propietarios tienen más de 200 hectáreas de tierra (INEC, 2017 citado en Ramón et al., 2018). Estos datos muestran las diferencias marcadas entre pequeños y grandes productores donde más del $50 \%$ de los agricultores de la provincia tienen pequeñas parcelas, muchos de estos presentan índices de pobreza y extrema pobreza, y la ciudad de Quito presenta el mayor índice de Gini (Grado de Desigualdad en la Distribución del Ingreso) en Ecuador (Instituto Nacional de Estadísticas y Censos, 2019). El sector rural en el cantón Quito está cada vez más abandonado. De acuerdo con Ramón et al. (2018, 63) "el $4,6 \%$ de la población de éste se dedica a la agricultura, mientras que la cifra sube para la provincia de Pichincha, en la cual el $63 \%$ se dedica a actividades agropecuarias".

La edad promedio del agricultor sobrepasa los 60 años (Ramón et al., 2018) por lo que se deduce que cada vez hay menos gente que está trabajando en la actividad agrícola y es necesario proponer actividades alternativas para reactivar la producción primaria. Es importante mencionar que el cantón Quito solventa la demanda alimentaria de los consumidores únicamente en un $26 \%$, y la producción de la provincia de Pichincha es la que abastece mayormente al cantón en un 36\%, el resto de la demanda de la población 38\% es proporcionada por el excedente de producción de otras provincias (Ramón et al., 2018).

\subsection{ALIMENTOS EMBLEMÁTICOS DEL CANTÓN QUITO}

El maíz, la papa y el trigo son los productos base de la cocina tradicional ecuatoriana que han sido consumidos históricamente (tabla 2), a partir de los intercambios desarrollados entre las culturas andinas, de éstas con las mesoamericanas y de ambas con las del mediterráneo europeo.

El maíz tiene una fuerte connotación simbólica, siendo un ingrediente básico de la cotidianidad, ritualidad e identidad ecuatoriana (Unigarro, 2014). La presencia de este alimento fue parte de la cultura alimentaria de las poblaciones nativas que conforman el territorio ecuatoriano antes de la conquista inca y española, 
evidenciándose en restos de maíz de tiempos pre-cerámicos pertenecientes a sociedades nómadas (Unigarro, 2014). Es utilizado en sus diversas preparaciones: tierno, maduro y seco (Unigarro, 2014), desde tiempos remotos está presente en la vida diaria de la población, Murra $(1997$, p.186) menciona que "en las crónicas del siglo XVI hay muy poco acerca de ritos de la papa o la quinua, y que los calendarios de las ceremonias se limitan casi exclusivamente al maíz".

Por su parte, la papa es un cultivo procedente de los Andes. De acuerdo con Pumisacho (2011, p.14): "al parecer, su origen es de distintos centros de América del Sur: Perú, Bolivia y el sur de Chile, este cultivo se extendió en el territorio del Tahuantinsuyo". Respecto al trigo la tradición se remonta a la llegada de los españoles a Ecuador y desde ahí el pueblo mestizo de la sierra ecuatoriana, en este caso del cantón Quito, le ha dado un valor importante a través de su cocina tradicional.

Los alimentos tradicionales del cantón Quito están relacionados con productos alimentarios donde el maíz ocupa un $25 \%$, siguiéndole en importancia el trigo en un 19\% (INPC, 2017). De acuerdo con los turistas encuestados la papa es el principal alimento que identifica al cantón Quito $(17,8 \%)$ y en segundo lugar el maíz con un $13 \%$. Todos estos productos forman parte de la producción agroalimentaria local de la zona rural de Quito y es importante mencionar que no existe evidencia de que el turismo culinario haya generado beneficios significativos en las unidades de producción local de estos alimentos. Específicamente, los platos de comida que identifican al cantón Quito son: el hornado 20,37\%, la fritada 13,93\% y el locro $13,58 \%$, donde la papa es un ingrediente central (tabla 3). De acuerdo con un funcionario del Ministerio de Turismo del Ecuador (entrevista, 30 de abril del 2019) en el mapa gastronómico del Ecuador (MINTUR, 2018c) el locro de papas es el plato más representativo del cantón Quito. Para determinar la representatividad del alimento se tomaron en cuenta aspectos como: historia, ingredientes locales, tradición vigente y oferta en el destino; a cada uno de estos criterios se les asignó un puntaje de 25, para sumar un total de 100 puntos. Relacionando con este aspecto, la administradora del restaurante "Diosolopay" (entrevista, 06 de septiembre del 2019) menciona:

"El turista extranjero ya viene con la idea, directamente piden locro de papas, porque las agencias de viajes les venden esa imagen."

Por su parte, el trigo es un producto altamente consumido en el cantón Quito, principalmente a través del pan que forma parte de la alimentación diaria en desayunos y cenas. Sin embargo, el trigo es un producto que en su mayoría se importa, porque como nos comenta el técnico del INIAP especialista en este cereal (entrevista, 16 de septiembre del 2019):

"La producción de trigo no es fuerte en el país, no porque no se quiera producir, sino porque no ha habido políticas de incentivo en la producción. En los años 70 y 80 había mucha más superficie de trigo sembrada, cuando bajó la superficie se permitió la libre importación de trigo y a los productores no les convenía sembrar para competir con un trigo importado más barato".

Recientemente, ha habido un incremento en la producción de trigo porque el gobierno nacional estableció una política en cuanto al consumo. Hay una gran demanda de trigo por parte de los molinos porque el país impuso requisitos donde los que importan deben consumir trigo nacional por lo menos en un $1 \%$ de sus compras totales (entrevista a técnico del INIAP especialista en trigo, 16 de septiembre del 2019).

\subsection{Gastronomía tradicional en restaurantes locales}

De acuerdo con Pazos-Barrera (2010) la mayoría de productos alimentarios de Quito son resultado de la fusión de ingredientes, producido en el contexto de los intercambios comerciales con las poblaciones de la Sierra, la Costa y el Oriente; donde también hubo intercambio de utensilios, conocimientos y técnicas que son la base del patrimonio culinario de la ciudad (Romero, 2018). 
Tabla 2. Alimentos hechos con maíz, papa y trigo que se ofertan en los restaurantes emblemáticos del centro histórico de Quito.

\begin{tabular}{|c|c|}
\hline Ingrediente base & Alimento \\
\hline Maíz & $\begin{array}{l}\text { 1.- Tostado (maíz seco tostado para acompañar comidas) } \\
\text { 2.- Caca de perro (maíz seco tostado con panela) } \\
\text { 3.- Humitas (pasteles de maíz y queso cocinados al vapor envueltos en hoja de maíz) } \\
\text { 4.- Quimbolitos (pasteles dulces hechos con harina de maíz) } \\
\text { 5.- Fanesca (sopa de granos que incluye maíz) } \\
\text { 6.- Chicha de jora (bebida fermentada de germen de maíz) }\end{array}$ \\
\hline Papa & $\begin{array}{l}\text { 1.- Hornado (cerdo al horno de leña con papas) } \\
\text { 2.- Papas con cuero (papas cocinadas con cuero de cerdo) } \\
\text { 3.- Papas con librillo (estofado de papas con estomago de res) } \\
\text { 4.- Seco de chivo (estofado de chivo o borrego con arroz y papas) } \\
\text { 5.- Fritada (papas y carne de cerdo cocinada en su propia grasa) } \\
\text { 6.- Locro de papas (sopa espesa de papas) }\end{array}$ \\
\hline Trigo & $\begin{array}{l}\text { 1.- Bizcochos (pan crocante deshidratado a baja temperatura) } \\
\text { 2.- Moncaibas (masa dura y crocante preparada con mantequilla y azúcar) } \\
\text { 3.- Aplanchados (masa horneada de hojaldre cubierta por una capa de glaseado) } \\
\text { 4.- Melvas (galletas pegadas con mermelada de mora con una gota de chocolate) } \\
\text { 5.- Pristiños (masa de harina de trigo frita en forma de cruz) } \\
\text { 6.- Buñuelos (masas de harina frita) } \\
\text { 7.- Quesadillas (género de pastel con queso en forma estrella de harina de trigo y huevo) }\end{array}$ \\
\hline
\end{tabular}

Fuente: Elaboración propia.

En el discurso de las cocinas nacionalistas del siglo XIX la cultura indígena se excluía siempre (Back-Geller Corona, 2009) pero en la cocina patrimonial del siglo XXI ésta llega a ocupar un lugar protagónico al reconocer el proceso del mestizaje evidenciado en diversas culturas alimentarias (Aguilera, 2016; Laborde y Medina, 2015). Esto ha sucedido en Quito con la designación, como patrimonio cultural, de muchos alimentos mestizos del cantón Quito que anteriormente no eran valorados (tabla 3).

Por su parte los turistas extranjeros, pese al auge de las cocinas étnicas en el turismo, son proclives a consumir alimentos que guardan cierta similitud con su dieta habitual, evitando aquellos que son desconocidos y que les generan desconfianza, ya sea por los métodos de elaboración o por los ingredientes empleados (Cohen y Avieli, 2004). Siendo evidente que la concurrencia de turistas extranjeros en establecimientos emblemáticos del C.H.Q. es menor que la de turistas nacionales; e incluso en dos establecimientos de los 16 no llega ningún turista extranjero, probablemente porque la comida se distancia mucho de lo que habitualmente están acostumbrados a comer.

Algunos de estos establecimientos muestran la comida tradicional auténtica porque como dice Vásquez-Medina (2016) las dinámicas sociales que se dan en los restaurantes familiares y de pequeña escala suelen estar regidos por la nostalgia culinaria, transmitida al plano colectivo de las prácticas que se llevan a cabo en las cocinas. El turismo culinario en el C.H.Q. se circunscribe a los pequeños negocios de comida tradicional que existen desde muchos años atrás, enmarcándose en esta temática los restaurantes familiares, de carácter local e involucrados con el pueblo. Así se muestra en el "Salón Don Lucho" (entrevista, 05 de septiembre del 2019):

“Los que vienen son los que viven por acá, es gente local, hay ecuatorianos que viven en otros países, migrantes, y lo primero que saben es que en otros lados no se encuentran estas comidas, hay de todas partes del Ecuador, un 90 \% son locales, y viven en otros lados y vuelven; los extranjeros no vienen acá."

De acuerdo con Matta (2011) los ingredientes y alimentos que habían sido menospreciados se convierten hoy, a través de una política reivindicativa sustentada en la lógica económica de la competitividad, en objeto de orgullo. Así, muchos quiteños se reencuentran cuando van a estos establecimientos, es más llevan a amigos y parientes que vienen de otros países para mostrar con orgullo esta comida emblemática que se 
ofrece en estos lugares auténticos del C.H.Q. La herencia culinaria de Quito está contenida en recetarios que datan de la época colonial, cuyos platos han sido transmitidos de generación en generación, permitiendo el desarrollo social y económico de sus depositarios (Unigarro, 2010), por lo que su carácter de patrimonio cultural inmaterial cobra un mayor valor en el contexto del turismo culinario y de las políticas culturales relacionadas con la identidad (Long, 2018).

Tabla 3. Relación de los turistas con los alimentos emblemáticos.

\begin{tabular}{|c|c|}
\hline $\begin{array}{l}\text { Productos que los turistas identifican como base } \\
\text { de la dieta alimentaria del Ecuador }\end{array}$ & $\begin{array}{l}\text { papa: } 20,12 \% \\
\text { maíz: } 12,40 \% \\
\text { arroz: } 8,94 \% \\
\text { plátano y plátano verde, } 8,94 \% \\
\text { hortalizas: } 8,33 \% \\
\text { yuca*: } 7,11 \% \\
\text { cebada: } 6,50 \% \\
\text { pollo: } 6,10 \% \\
\text { otros: } 21,56 \%\end{array}$ \\
\hline $\begin{array}{l}\text { Productos alimentarios con los que los turistas } \\
\text { identifican al cantón Quito }\end{array}$ & $\begin{array}{l}\text { papa: } 17,8 \% \\
\text { maíz: } 13 \% \\
\text { cuy**: } 10,3 \% \\
\text { melloco***: } 9,5 \% \\
\text { cebada: } 9 \% \\
\text { avena: } 8,8 \% \\
\text { chochos: } 8,5 \% \\
\text { otros: } 23.1 \%\end{array}$ \\
\hline $\begin{array}{l}\text { Plato de comida con el que los turistas identifican } \\
\text { al cantón Quito }\end{array}$ & $\begin{array}{l}\text { hornado: } 20,37 \% \\
\text { fritada: } 13,93 \% \\
\text { locro de papas: } 13,58 \% \\
\text { cuy con papas: } 11,11 \% \\
\text { mellocos con habas: } 7,71 \% \\
\text { chochos con tostado: } 6,79 \% \\
\text { otros: } 26,51 \%\end{array}$ \\
\hline Interés por la comida tradicional & Si: $88,7 \%$ No: $11,3 \%$ \\
\hline Interés por el turismo culinario & Si: $93,33 \%$ No: $6,67 \%$ \\
\hline $\begin{array}{l}\text { Intereses específicos relacionados con el turismo } \\
\text { culinario }\end{array}$ & $\begin{array}{l}\text { Aprender a preparar platos tradicionales: } 45,65 \% \\
\text { Conocer sobre siembra, cosecha y otros: } 25 \% \text { Probar platos tradi- } \\
\text { cionales: } 14,13 \% \\
\text { Conocer sobre las tradiciones del alimento: } 12,5 \% \text { Fotografía de } \\
\text { los alimentos: } 1,63 \% \\
\text { Conocer la procedencia de los alimentos } 1,08 \%\end{array}$ \\
\hline $\begin{array}{l}\text { Ingreso mensual promedio del turista nacional } \\
\text { (USD) }\end{array}$ & $\begin{array}{l}\text { 200-349: } 4,42 \% \\
\text { 350-499: } 41,44 \% \\
\text { 500-649: } 21,55 \% \\
\text { 650-899: } 13,26 \% \\
900-1299: 13,26 \% \\
\text { 1300-2299: } 4,97 \% \\
2300 \text { o más: } 1,10 \%\end{array}$ \\
\hline
\end{tabular}

*raíz sembrada en áreas tropicales

**mamífero originario de la zona andina

***tubérculo de la zona andina

Fuente: Elaboración propia con base en trabajo de campo (2017).

Para Avieli (2013) no es tan fácil encontrar la autenticidad en destinos turísticos, si bien porque no existe como tal en algunos destinos que se han modernizado, o porque se cree que la vida auténtica de los lugareños disuade a los turistas; así, la industria turística participa en la organización de la autenticidad, es decir, en la creación y realización de sitios y eventos que parecen auténticos y atractivos para los turistas. Sin 
embargo, aunque esto sucede en la modernidad de muchos establecimientos de alimentos, los del C.H.Q. siguen conservando su singularidad, a partir de normas de consumo construidas en función de sabores, precios e ingredientes, que sólo suelen ser detectadas por los "conocedores" locales.

Para Prats (2011), existen dos fenómenos en apogeo: por un lado, la necesidad de rescatar la gastronomía local frente a la alimentación industrial masificada; y, por otro, el debilitamiento de la oferta turística convencional, que requiere el desarrollo de nuevos productos y servicios relacionados con la cultura y los recursos propios de cada territorio. Este aspecto es positivo al relacionarlo con un público, que está buscando alternativas a la estandarización cultural del mundo global.

La población local siente que en algunos establecimientos turísticos no existe una comida auténtica y de calidad (Avieli, 2013). Sin embargo, los establecimientos emblemáticos del C.H.Q., aunque algunos son turísticos, no se han involucrado en esta lógica de escenificación de lo auténtico, puesto que la mayoría de sus clientes son consumidores que tienen el capital cultural para reconocer un plato original. Por tanto, es fundamental poner atención en el papel que juega el turismo contemporáneo en la co-producción del patrimonio (Gravari-Barbas, 2018) que en el caso específico del turismo culinario del C.H.Q., presenta un gran potencial para la consolidación del patrimonio gastronómico como motor de desarrollo local que no ha sido explorado plenamente.

\subsection{Relación de la comida emblemática con la producción local}

Un aspecto fundamental que se ha intentado dilucidar en este trabajo es el papel que juega la comida tradicional en la construcción del producto turístico local, con lo que se observa que las identidades alimentarias, reflejadas en los servicios turísticos suelen contener una representación del territorio y de su gente (Du Rand et al., 2003; Frochot, 2003).

Sólo el 43,75\% de los establecimientos de comida emblemática del C.H.Q. compran, semanalmente y de manera directa, algunos productos alimentarios a los productores locales y de otras provincias. La Cafetería "El Buen Café" compra leche y tomate de árbol mientras que los vegetales y las moras ellos mismos los producen. El Restaurante San Agustín, compra cordero; la Procesadora de Café Águila de Oro compra café; la Cafetería Modelo compra cordero; la Fonda de Mama Miche compra cerdo, pollos y morocho; la Confitería Kukurucho del Maní compra maní; el Restaurante Diosolopay compra naranjilla y babaco. Esta compra directa se hace a los productores de algunas parroquias rurales del cantón Quito como: San José de Minas, Pomasqui, Nanegal y Lloa; así como a productores de otras localidades de la provincia de Pichincha como: Machachi y Sangolquí. También se adquieren productos de otras provincias como Loja, Cotopaxi, Esmeraldas y provincias del Oriente (tabla 4).

Se observa entonces que una parte de la comida emblemática del C.H.Q. si proviene de pequeños productores locales, sin embargo, hace falta que se dé más valor a sus productos desde una acción concertada y más estructurada. Los establecimientos del C.H.Q. que compran directamente al productor lo hacen por abaratar precios en muchos de los casos y por tener un productor conocido que les entrega calidad en el producto, entre otras razones (entrevistas a establecimientos alimentarios, septiembre 2019- enero 2020).

Es importante tomar en cuenta el volumen de compra a intermediarios $62,5 \%$ y en los mercados $56,25 \%$ (tabla 4). Los mercados referidos son: San Roque y Mayorista (mayoristas ambos) La Ofelia y Santa Clara (detallistas); donde hay una oferta de productos que vienen de todas las provincias y a precios más bajos de los que se producen en la provincia de Pichincha. Al respecto, Ramón et al. (2018) mencionan que los productos que vienen a Quito provienen de provincias aledañas ofreciéndose en el mercado mayorista (48 \%) y el restante se distribuye entre supermercados, hoteles, restaurantes, cafeterías y ferias.

Los mercados mayoristas concentran las mayores ventas, al proveer a más del $66 \%$ de la totalidad de comerciantes minoristas de la ciudad (Ramón et al., 2018). Estos mercados son los principales centros de aprovisionamiento de alimentos en Quito, de donde obtienen sus insumos gran parte de los establecimientos de comida del centro histórico. 
En el salón de Don Lucho nos comentan (entrevista 6 de septiembre del 2019):

"Los productos compro en el mayorista, las papas en San Roque que está cerca, y el librillo me traen a entregar, y el coco compro en el mercado"

Según un técnico especialista en papa del INIAP (entrevista, 16 de septiembre del 2019) existe una calidad diferenciada de la papa que se produce en la provincia de Pichincha en el cantón Mejía, el cual a pesar de no pertenecer al cantón Quito, si puede considerarse parte de las periferias rurales de la ciudad. Sin embargo, tanto los intermediarios como los establecimientos alimentarios no siempre prefieren la papa de mejor calidad sino aquella que proporciona mayores ganancias.

Existe un distanciamiento creciente entre las cocinas tradicionales y los productos locales dado el alto nivel de intermediarios que están presentes en las cadenas de distribución, que privilegian los intercambios lucrativos antes que la calidad agroalimentaria. Pero, de acuerdo con Poulain (2019), el acto de comer representa un lazo entre el ser humano y la naturaleza, por lo que la cocina tradicional y/o emblemática debería incluir productos locales, además de permitir a sus productores tener una vida digna. Los alimentos emblemáticos del Centro Histórico de Quito deberían reflejar esta característica de anclaje territorial, para estar en condiciones de hablar de un verdadero patrimonio culinario. Por su parte, Contreras (2007) explica que los intereses de las sociedades contemporáneas afectan a los productos patrimoniales, a los contextos de producción y consumo, mismos que pueden haber cambiado considerablemente e incluso apartarse de las tradiciones.

Cuando un establecimiento alimentario ofrece una comida tradicional o "auténtica" sería importante que no sólo se enfocará en la mesa y en el plato, sino que su narrativa de autenticidad se extendiera hasta la producción primaria de sus ingredientes, basándose en la complementariedad entre turismo y agricultura local y no en la subordinación de la segunda a la primera (Medina, 2017). Esta relación se torna difícil dada la gran cantidad de intereses que están presentes en los mercados agroalimentarios y turísticos.

Es necesario entonces dar valor a los productos provenientes de las localidades cercanas y que vengan directamente del productor o máximo de un intermediario para tener una cadena de distribución más justa (Leal Londoño, 2015). De acuerdo con Gascón (2018) la patrimonialización y la conversión de la comida en atractivo turístico puede ayudar a revalorizar el modelo de producción campesino que provee sus materias primas, relacionándolo con alimentos de calidad, en contraste con la agroindustria global, fuertemente contaminada y homogeneizada de paisajes y alimentos. Esta premisa es difícil de consolidarse en la práctica.

El caso de los establecimientos emblemáticos del C.H.Q. muestra que los productos base de la cocina local (maíz, papa y trigo) están atados a cadenas de comercialización fuertemente establecidas, donde los agricultores ganan poco o son excluidos. Todos los establecimientos coincidieron en que adquieren estos productos a través de intermediarios. Lo anterior, ha incidido en una pérdida de la diversidad culinaria, pues las variedades de papa y maíz empleadas anteriormente se van sustituyendo por razas genéricas que producen platos inespecíficos. En el caso del trigo se pierde la oportunidad de desarrollar un sistema productivo nacional y existe una fuerte dependencia alimentaria hacia el exterior.

Algunas experiencias muestran que una forma de valorizar el patrimonio agroalimentario es a través de modelos productivos vinculados al turismo y al desarrollo territorial (Espeitx, 2004). De acuerdo con Ilbery y Maye (2005) existen ejemplos de la vinculación entre agricultura y turismo, pero mayormente en contextos agroindustrializados y de producción masiva de alimentos. Sin embargo, la transición hacia un sistema alternativo que incluya a la producción local está relacionado con los patrones de consumo, regidos por preocupaciones ambientales, éticas, sociales, culturales y de salud (Ilbery y Kneafsey, 1998; Renting et al., 2003; Ilbery y Maye, 2005)

Se puede observar que el consumidor que acude a los establecimientos emblemáticos del C.H.Q. se enfoca en aspectos relacionados con el sabor, la autenticidad y la tradición. Aunque sus preocupaciones respecto cuestiones ambientales, éticas y de salud no son centrales, su búsqueda por la comida de "antes" tiene una estrecha relación con insumos de calidad provenientes de los pequeños productores locales. Se trata de un consumidor que se desliga de las tendencias homogéneas actuales y eso se demuestra a través del consumo diferenciado (Bourdieu, 1998), en el que se relacionan productos, terruño y actores sociales (Agudelo-López, Cesin-Vargas y Thomé-Ortiz, 2016). 
Tabla 4. Características de los restaurantes emblemáticos del Centro Histórico de Quito.

\begin{tabular}{|c|c|c|c|c|c|c|c|c|}
\hline \multirow[t]{2}{*}{ No. } & \multirow[t]{2}{*}{ Establecimiento } & \multirow{2}{*}{$\begin{array}{l}\text { Número total } \\
\text { de platos } \\
\text { ofrecidos }\end{array}$} & \multirow{2}{*}{$\begin{array}{c}\text { Platos } \\
\text { tradicionales } \\
\text { ofrecidos }\end{array}$} & \multicolumn{3}{|c|}{ Lugar de compra de alimentos } & \multirow{2}{*}{$\begin{array}{c}\text { Recibe } \\
\text { turistas } \\
\text { nacionales }\end{array}$} & \multirow{2}{*}{$\begin{array}{c}\text { Recibe } \\
\text { turistas } \\
\text { extranjeros }\end{array}$} \\
\hline & & & & 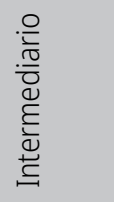 & $\begin{array}{l}\frac{0}{0} \\
\frac{0}{0} \\
\frac{0}{2}\end{array}$ & 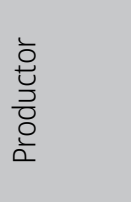 & & \\
\hline 1 & Cafetería Bodega Meneses & 17 & $\begin{array}{c}9 \\
(52,94 \%)\end{array}$ & $x$ & $x$ & - & $x$ & $x$ \\
\hline 2 & Cafetería El Buen Café Quito & 10 & $\begin{array}{c}6 \\
(60 \%) \\
\end{array}$ & - & $x$ & $x$ & $x$ & - \\
\hline 3 & Cafetería El Pretil de Alicia & 23 & $\begin{array}{c}11 \\
(47,83 \%)\end{array}$ & $x$ & - & - & $x$ & $x$ \\
\hline 4 & $\begin{array}{l}\text { Dulcería Cafetería: Colaciones Cruz } \\
\text { Verde }\end{array}$ & 10 & $\begin{array}{c}8 \\
(80 \%) \\
\end{array}$ & $x$ & - & - & $x$ & $x$ \\
\hline 5 & Heladería-Restaurante San Agustín & 72 & $\begin{array}{c}31 \\
(43,06 \%)\end{array}$ & $x$ & - & - & $x$ & $x$ \\
\hline 6 & Procesadora Café Águila de Oro & 3 & $\begin{array}{c}3 \\
(100 \%) \\
\end{array}$ & - & - & $x$ & $x$ & $x$ \\
\hline 7 & Restaurante y Cafetería Modelo & 50 & $\begin{array}{c}25 \\
(50 \%)\end{array}$ & $x$ & $x$ & $x$ & $x$ & $x$ \\
\hline 8 & $\begin{array}{l}\text { Restaurante Cafetería Mr. Meneses } \\
\text { e hijos }\end{array}$ & 40 & $\begin{array}{c}20 \\
(50 \%)\end{array}$ & $x$ & - & $x$ & $x$ & $x$ \\
\hline 9 & Fonda Mama Miche & 10 & $\begin{array}{c}8 \\
(80 \%) \\
\end{array}$ & - & $x$ & $x$ & $x$ & $x$ \\
\hline 10 & $\begin{array}{l}\text { Confitería artesanal Kukurucho } \\
\text { del Maní }\end{array}$ & 18 & $\begin{array}{c}16 \\
(88,88 \%)\end{array}$ & $x$ & $x$ & $x$ & $x$ & $x$ \\
\hline 11 & Ponches Magolita & 1 & $\begin{array}{c}1 \\
(100 \%) \\
\end{array}$ & $x$ & - & - & $x$ & $x$ \\
\hline 12 & Restaurante Diosolopay & 85 & $\begin{array}{c}29 \\
(34,12 \%)\end{array}$ & - & $x$ & $x$ & $x$ & $x$ \\
\hline 13 & Restaurante La Colmena & 6 & $\begin{array}{c}5 \\
(83,33 \%) \\
\end{array}$ & - & $x$ & - & $x$ & $x$ \\
\hline 14 & Salón Don Lucho & 6 & $\begin{array}{c}6 \\
(100 \%) \\
\end{array}$ & $x$ & $x$ & - & $x$ & - \\
\hline 15 & Picantería Laurita & 7 & $\begin{array}{c}6 \\
(85,71 \%) \\
\end{array}$ & - & $x$ & - & $x$ & $x$ \\
\hline \multirow[t]{2}{*}{16} & Heladería y Cafetería Caribe & 30 & $\begin{array}{c}18 \\
(60 \%)\end{array}$ & $x$ & - & - & $x$ & $x$ \\
\hline & Promedio / Porcentaje & $\begin{array}{l}24,26 \\
\text { platos }\end{array}$ & $69,74 \%$ & $62,5 \%$ & $56,25 \%$ & $43,75 \%$ & $100 \%$ & $87,5 \%$ \\
\hline
\end{tabular}

Fuente: Elaboración propia con base en entrevistas a establecimientos alimentarios emblemáticos C.H.Q (agosto 2019-abril 2020).

Los alimentos emblemáticos tienen una estrecha relación con los productos de proximidad, siendo el turismo culinario una herramienta para promover y preservar estos sistemas productivos que muchas veces no son viables a través de sus canales de distribución convencional. Tal como lo expresó una productora de maíz y papá (entrevista 15 de enero de 2019):

“Nosotros sólo perdemos y estamos subvencionando a los intermediarios son ellos que ganan”. 
El modelo de acaparamiento e intermediarismo que históricamente han enfrentado estos pequeños productores ya no es sostenible desde el punto de vista económico, por lo que es necesario pensar en procesos de acortamiento de la cadena de distribución, así como en agregación y generación de valor. El turismo culinario puede ser una alternativa en este sentido. De acuerdo con Espeitx (2008), la oferta desmedida de productos agroalimentarios masificados ha generado un espacio que busca dar valor a estrategias que llevan a enaltecer los productos de la tierra como patrimonio alimentario de la sociedad.

\subsection{Implicaciones sociales para la articulación entre turismo culinario y alimentos locales}

La patrimonialización de los alimentos tradicionales, responde a estrategias de promoción y a mercados alternativos que implican la acción concertada de actores clave como el Estado, los movimientos de consumidores y las organizaciones de productores. Estas estrategias se han orientado a la construcción de lazos confianza entre productores y consumidores, aspecto que no puede garantizar el mercado masivo de alimentos (Leal Londoño, 2015).

Es justamente el fortalecimiento del capital social lo que necesitan los pequeños productores de Latinoamérica para construir procesos de transformación socioeconómica del territorio, que impacten en mejoras tangibles en la calidad de vida y que satisfagan las demandas de los consumidores en cuanto a productos de calidad.

Sin embargo, en el C.H.Q. muchos de los productos son traídos por intermediarios debido a que para éstos es más fácil la entrega que para los pequeños productores. A ello hay que sumar la inconsistencia en las entregas de los productores locales, la precaria oferta de productos que se pueden producir a nivel local y que al productor no le gusta vender por cantidades pequeñas como necesitan estos establecimientos (entrevistas realizadas en restaurantes emblemáticos del C.H.Q, septiembre 2019- enero 2020).

El aporte del turismo al desarrollo territorial se relaciona con la oportunidad de generar una salida a la producción agroalimentaria local, a través de ventas directas, pero también ayuda a articular los productos de la tierra con las mesas y los platillos. Al respecto, los Sistemas Agroalimentarios Localizados pueden constituir atractivos turísticos que involucren el desarrollo territorial, en la medida en que se relacionen con una canasta de bienes y servicios que sirva como base y vehículo para la actividad turística (Blanco, 2012).

En el cantón Quito existen asociaciones de productores urbanos y periurbanos liderados por AGRUPAR, los cuales venden sus productos en 15 ferias establecidas en ciertos lugares de la ciudad y alrededores (entrevista a encargada del programa AGRUPAR, 27 de septiembre del 2019). Además, existe una organización de agricultores "El Porvenir de Romerillo" y "Manos Unidas" financiados por el Programa Coreano de Agricultura Internacional (KOPIA, por sus siglas en inglés) que trabajan en conjunto con el Instituto Nacional de Investigaciones Agropecuarias (INIAP) en circuitos cortos agroalimentarios en el cantón Mejía, población cercana al cantón Quito que pertenece a la provincia de Pichincha.

Estas asociaciones de productores entre otras podrían relacionarse con los establecimientos de comida emblemática del C.H.Q., a través de una estrategia de comercio justo. Sin embargo, un técnico especialista en manejo de papa en el INIAP nos comenta (entrevista, 16 de septiembre del 2019):

“En el 2018 se buscó restaurantes que quisieran el chip solidario (los que están dispuestos a pagar por un producto de calidad, precio justo, y que te pague bien) a través de Shamugñan. En el C.H.Q. no están dispuestos a pagar por calidad, ellos quieren cantidad y lo que venga, hicimos el sondeo en 20 restaurantes y ninguno está interesado en comprar a Shamugñan"

De Jesús-Contreras et al. (2017, p. 553) afirman que: "la valorización turística de los alimentos locales puede constituir un proceso de patrimonialización en la medida en que ello implique la activación de sus significados, así como la movilización de actores y su vinculación con el territorio". De esta manera, los establecimientos que hacen parte del patrimonio cultural del Ecuador deberían involucrar a actores de la localidad a través de la compra de productos agrícolas a precios justos para tener esta denominación patrimonial de manera más justa y real. 
En Pichincha, los precios del productor son cerca del $63 \%$ más bajos que los precios a los cuales se expende el mismo producto en centros mayoristas y minoristas (Ramón et al., 2018). Esto nos muestra la realidad de la comercialización en Quito, donde el productor es el que menos gana. Lo cual tiene una estrecha relación con las dificultades para organizarse en la escala territorial entre diversos actores locales como lo evidencia la relación entre establecimientos de comida emblemática del C.H.Q. con los productores de alimentos.

\section{CONCLUSIONES}

Los productos alimentarios emblemáticos del Centro Histórico de Quito tienen como base principal el maíz, el trigo y la papa. Sin embargo, el maíz y la papa han experimentado una disminución en cuanto a su producción, debido a que el crecimiento urbano se ha consolidado en detrimento de las zonas de producción agropecuaria. Respecto al trigo, su producción se ha visto incrementada en los últimos años con el estímulo de políticas de Estado; pero dicho crecimiento también se acompaña de una mayor dependencia del grano producido en el exterior, vinculada con la apertura para su libre importación.

Se observa que el establecimiento de relaciones comerciales entre la oferta culinaria emblemática y los productores locales podría generar mejores condiciones de vida para la población rural y podría mejorar la calidad de los alimentos ofertados. Sin embargo, para que ello ocurra es necesaria la concurrencia entre organismos públicos y privados, siendo los gobiernos provinciales y locales quienes tienen la facultad de instrumentar políticas que incentiven el comercio de proximidad y justo.

Los establecimientos de alimentos emblemáticos del C.H.Q. compran la mayoría de sus insumos a través de intermediarios que facilitan la entrega, de bienes variados a precios competitivos, simultáneamente, compran en mercados algunos productos que les representan mayor conveniencia por su precio o características y, en menor medida, adquieren alimentos de productores locales que se caracterizan por la calidad reconocida de sus productos. Dado que la participación de los productores locales en la oferta turística culinaria es marginal, se observa la necesidad de estrechar los vínculos entre estos establecimientos y los productores locales, a través de políticas que incentiven la compra local y de estrategias de comunicación que informen a los consumidores.

El turista culinario del C.H.Q. valora los establecimientos emblemáticos puesto que apelan a su nostalgia, representando una oportunidad de reencontrarse con su pasado, a través de los lugares y sus sabores. Sin embargo, este ejercicio de memoria alimentaria no necesariamente integra el origen de los alimentos, lo cual denota una percepción parcial sobre la calidad de la cocina emblemática que no se extiende hasta los productos de la tierra.

Falta generar una compresión profunda de las cocinas tradicionales y su relación con los productos locales. El sistema agroalimentario global ha estimulado una ruptura entre las expresiones gastronómicas, los procesos de transformación y los insumos utilizados, en aras de fortalecer una economía deslocalizada y sustitucionista. Lo anterior, atenta directamente contra el origen de las cocinas emblemáticas y representa una paradoja para el turismo que se base en estos bienes patrimoniales.

Esta transformación requiere un trabajo de concientización en múltiples niveles, que incluya la propia valorización que los productores hagan de su labor y sus productos, de los establecimientos que los contemplen como insumos de calidad que deben ser bien pagados, por parte del gobierno que considere al turismo como una estrategia de desarrollo y de redistribución de la riqueza; y por los consumidores que a través de sus prácticas exijan productos de calidad, auténticos y ligados al territorio.

El presente trabajo es una primera aproximación a la relación entre producción agroalimentaria local y turismo culinario en centros históricos, por lo que futuras investigaciones deberían enfocar problemáticas más específicas de los restauranteros locales y de los pequeños productores, la percepción de los consumidores respecto a los alimentos emblemáticos y el papel del Estado en el diseño de políticas que estimulen el desarrollo territorial. 


\section{AGRADECIMIENTOS}

Agradecemos el apoyo de la Dirección de Investigación de la Universidad Central del Ecuador (Resolución RCE-S.O 015 No.108-2019), para la realización de este artículo como resultado del proyecto No.363-19 “Patrimonialización de los recursos locales alimentarios a través de la oferta culinaria del Centro Histórico de Quito". Igualmente se agradecen las facilidades administrativas proporcionadas por la Universidad Autónoma del Estado de México, a través del Instituto de Ciencias Agropecuarias y Rurales para la movilidad internacional de los autores.

\section{REFERENCIAS}

Agudelo-López, M. A., Cesin-Vargas, A. y Thomé-Ortiz, H. (2016). Alimentos Emblemáticos y turismo. La vinculación del queso bola de ocosingo con la oferta turística regional. Agricultura, Sociedad y Desarrollo, 13 (1), 131-149. Recuperado de https://www.aacademica.org/humberto.thome.ortiz/17.pdf

Aguilera Bornand, I. (2016). De la cocina al estado nación. El ingrediente mapuche. Barcelona: Icaria.

Aguirregoitia Martínez, A. y Fernández Poyatos, M.D. (2017). La Gastronomía como recurso turístico en la provincia de Alicante. International Journal of Scientific Management and Tourism, 3(3), 25-48. Recuperado de https://rua.ua.es/ dspace/bitstream/10045/68592/1/2017_Aguirregoitia_Fernandez_IJOSMT.pdf [25-09-2019]

Alonso, A.D. y Liu, Y. (2011). The potential for marrying local gastronomy and wine; the case of the fortunate islands. International Journal of Hospitality Management, 30, 974-981. https://doi.org/10.1016/j.ijhm.2011.02.005

Avieli, N. (2013). What is 'local food?' Dynamic culinary heritage in the world heritage site of hoi an, Vietnam. Journal of Heritage Tourism, 8(2-3), 120-132. https://doi.org/10.1080/1743873X.2013.767812

Ávila-Sánchez, H. (2005). Lo urbano-rural, ¿Nuevas expresiones territoriales?. México: Universidad Nacional Autónoma de México.

Back-Geller Corona, S. (2009). Los recetarios afrancesados del siglo XIX en México, Anthropology of food, S6. https://doi. org/10.4000/aof.6464

Barrera, E. (2009). Las rutas alimentarias como instrumento para el desarrollo territorial: el caso de la Ruta Argentina de la Yerba Mate de. Revista de la Universidad de Sonora. 26, 19-22. Recuperado de https://www.agro.uba.ar/users/ barrera/publicaciones/RUTAS\%20ALIMENTARIAS.\%20ARQUITECTURA\%20TURISTICA.pdf

Bessière, J., Poulain, J. P. \& Tibère, L. (2013). L'alimentation au cœur du voyage. Le rôle du tourisme dans la valorisation des patrimoines alimentaires locaux. Mondes du Tourisme,71-82. Recuperado de https://hal.archives-ouvertes.fr/ hal-01465053 [10-01-2020]

Blanco, M. (2012). La activación de los SIAL vía el agroturismo: análisis del potencial de articulación en cuatro territorios queseros de América Latina. Agroalimentaria, 18 (34), 123-131. Recuperado de http://erevistas.saber.ula.ve/index. php/agroalimentaria/article/view/4119 [25-10-2019]

Blas-Yánez, S., Thomé-Ortiz, H., Espinosa-Ortega, A. y Vizcarra-Bordi, I. (2018). La construcción discursiva del patrimonio agroalimentario en las sociedades contemporáneas: aproximaciones conceptuales y debates teóricos. Revista Mexicana de Ciencias Agrícolas, 9(2), 443-457. http://dx.doi.org/10.29312/remexca.v9i2.1084.

Bourdieu, P. (1998). La distinción. Criterios y bases sociales del gusto. Madrid: Grupo Santillana de Ediciones S.A.

Bowen, S. y Mutersbaugh, T. (2013). Local or localized? Exploring the contributions of Franco-Mediterranean agrifood theory to alternative food research. Agriculture and Human Values, 31, 201-213. https://doi.org/10.1007/s10460013-9461-7

Cohen, E. \& Avieli, N. (2004). Food in tourism. Attraction and impediment. Annals of Tourism Research, 31(4), 755-778. https://doi.org/10.1016/j.annals.2004.02.003

Contreras, J. (2007). El patrimonio alimentario en el área mediterránea. En J. Tresserras y F. X. Medina (Eds.) Patrimonio gastronómico y turismo cultural en el Mediterráneo. Barcelona: Universitat de Barcelona.

Contreras, J. y Gracía Arnaiz M. (2005). Alimentación y cultura: perspectivas antropológicas. Barcelona: Ariel.

Cresswell, J. (2007). Qualitative inquiry and research design: choosing among five traditions. Londres: Sage Publications. 
De Jesús-Contreras, D., Thomé-Ortiz, H., Espinoza-Ortega, A. y Vizcarra-Bordi, I. (2017). Turismo Agroalimentario. Una perspectiva recreativa de los alimentos emblemáticos desde la geografía del gusto. Estudios y Perspectivas en Turismo, 26(1), 549-567. Recuperado de https://dialnet.unirioja.es/servlet/articulo?codigo=6328654 [10-06-2019]

D'Amico, A. (2004) The enhancement of the typical products value: From commodity to Experience. The case of Esperya. com. British Food Journal, 106 (10-11), 793-805. http://doi.org/10.1108/00070700410561397

Du Rand, G.E., Heath, E. \& Alberts, N. (2003). The role of local and regional food in destination marketing: A South African situation analysis. Journal of Travel \& Tourism Marketing, 14 (3-4), 97-112. http://doi.org/10.1300/J073v14n03_06

Du Rand, G.E. \& Heath, E. (2006). Towards a framework for food tourism as an element of destination marketing. Current Issues in Tourism, 9 (3), 206-234. http://doi.org/ 10.2164/cit/226.0

Esper, S. C. (2011). El desafío de las técnicas cualitativas en el diagnóstico organizacional: El uso de la teoría enraizada. Buenos Aires: Asociación Civil para el Estudio de las Políticas Públicas Participativas.

Espeitx, E. (2004). Patrimonio alimentario y turismo: una relación singular. PASOS Revista de Turismo y Patrimonio Cultural, 2(2), 193-213. https://doi.org/10.25145/j.pasos.2004.02.016

Espeitx, E. (2008). Los sentidos del patrimonio alimentario en el sur de Europa. En: M. Álvarez y X. Medina (coord). Identidades en el plato El patrimonio cultural alimentario entre Europa y América (pp: 45-61). Barcelona: Icaria.

Espinoza Tames, P., Hernández Sinencio, H., López Guzmán, R. y Lozano Esparsa, S. (2018). Muestreo de bola de nieve. México: Universidad Nacional Autónoma de México.

Forney, J. \& Häberli, I. (2016). Introducing 'seeds of change' into the food system? Localisation strategies in the Swiss dairy industry. Sociología Ruralis, 56, 135-156. https://doi.org/10.1111/soru.12072

Fritscher, M. (2002). Globalización y alimentos: tendencias y contratendencias. Política y Cultura, 18, 61-82. Recuperado de https://www.redalyc.org/pdf/267/26701804.pdf [22-01-2020]

Frochot, I. (2003). An analysis of regional positioning and its associated food images in french tourism regional brouchers. Journal of Travel and Tourism Marketing. 14(3-4), 77-96. https://doi.org/10.1300/J073v14n03_05

Fusté-Forné, F. (2015). El turisme gastronòmic: autenticitat i desenvolupament local en zones rurals. Documents d'Anàlisi Geogràfica, 61 (2), 289-304. https://doi.org/10.5565/rev/dag.218

Fusté-Forné, F. (2016). Los paisajes de la cultura: la gastronomía y el patrimonio culinario. Dixit, 24, 04-16. Recuperado de http://www.scielo.edu.uy/scielo.php?script=sci_arttext\&pid=S0797-36912016000100001\&lng=es\&nrm=iso> [08-06-2020]

Gascón, J. (2018). Turismo, agricultura y alimentación. De la Teoría del Enlace a la patrimonialización de la gastronomía. En F. X. Medina y P. Leal Londoño (Eds.) Gastronomía y turismo en Iberoamérica (pp: 15-32). Gijón: Trea.

Gobierno Provincial de Pichincha (2017). Distrito Metropolitano de Quito. Recuperado de https://www.pichincha.gob.ec/ cantones/distrito-metropolitano-de-quito

Goodman, D. (2004). Rural Europe redux? Reflections on alternative agro-food networks and paradigm change. Sociologia Ruralis, 44, 3-16. https://doi.org/10.1111/j.1467-9523.2004.00258.x

Goulding, C. (2009). Grounded theory perspectives in organizational research. En D. A. Buchanan and A. Bryman (Eds), Handbook of Organizational Research Methods (pp.381-394). London: Sage.

Gravari-Barbas, M. (2018). Tourism as a heritage production machine. Tourism Management Perspectives, 25, $173-176$. https://doi.org/10.1016/j.tmp.2017.12.002

Hall, C.M. \& Mitchell, R. (2001). Wine and food tourism. En: N. Douglas, N. Douglas and R.Derrett (Eds.). Special interest Tourism: Context and cases (pp. 307-329). Brisbane, Australia: John Wiley \& Sons.

Hall, M., Mitchell, R., Sharples, L., Maciones, N. \& Combourne B.( 2003). Food Tourism Around The World, London: Elsevier.

Hernández-Mogollon, J. M., Di-Clemente, E. y López Guzmán, T. (2015). El turismo gastronómico como experiencia cultural. el caso práctico de la ciudad de Cáceres (España). Boletín de la Asociación de Geógrafos Españoles, 68, 407-427. https://doi.org/10.21138/bage.1868

Ilbery, B. \& Maye, D. (2005). Alternative (shorter) food supply chains and specialist livestock products in the Scottish English borders. Environment and Planning A: Economy and Space, 37(5), 823-844. https://doi.org/10.1068/a3717

INEC (Instituto Nacional de Estadísticas y Censos) (2020). Proyección de la población ecuatoriana, por años calendario, según cantones (2010-2020). Recuperado de https://www.ecuadorencifras.gob.ec/proyecciones-poblacionales/ [08-06-2020] 
INEC (Instituto Nacional de Estadísticas y Censos) (2019). Encuesta Nacional de Empleo, Desempleo y Subempleo(ENEMDU), Quito. Recuperado de https://www.ecuadorencifras.gob.ec/documentos/webinec/EMPLEO/2019/Junio/201906_ Mercado_Laboral_final.pdf [20-04-2020]

INPC (Instituto Nacional de Patrimonio Cultural) (2017). Bienes patrimoniales inmateriales. In Sistema de Información del Patrimonio Cultural Ecuatoriano (SIPCE). Quito. Recuperado de http://sipce.patrimoniocultural.gob.ec:8080/IBPWeb/ paginas/busquedaBienes/busquedaPrincipal.jsf [10-03-2020]

Jiménez-Beltrán, F.J., López-Guzmán, T. y González Santa Cruz, F (2016). Analysis of the Relationship between Tourism and Food Culture. Sustainability, 8 (418), 1-11. https://doi.org/10.3390/su8050418

Kivela, J. \& Crotts, C. (2006). Tourism and Gastronomy: Gastronomy's Influence on How Tourists Experience a Destination. Journal of Hospitality \& Tourism Research, 30, 354-377. https://doi.org/10.1177/1096348006286797

Laborde, G. y Medina, F. X. (2015). De los recetarios nacionales a los expedientes patrimoniales: cocinas, identidades y políticas estatales entre América y Europa. En R. Ávila, M. Álvarez, y F. X. Medina (Eds.), Alimentos cocinas e intercambios culinarios. Confrontaciones culturales, identidades, resignificaciones (pp.89-104). Guadalajara: Universidad de Guadalajara.

Libery, B. \& Kneafsey, M. (1998). Product and Place: Promoting Quality Products and Services in the Lagging Rural Regions of the European Union. European Urban and Regional Studies, 5(4), 329-341. https://doi. org/10.1177/096977649800500404

Leal Londoño, M. (2015). Turismo gastronómico, impulsor del comercio de proximidad. Barcelona-España: UOC. Recuperado de https://www.libreriaproteo.com/libro/ver/1709184-turismo-gastronomico.html [28-10-2019].

Long, L. (2018). Cultural politics in culinary tourism with ethnic foods. Revista de Administração de Empresas, 58 (3), 316 324. https://doi.org/10.1590/s0034-759020180313

Matta, R. (2011). Posibilidades y límites del desarrollo en el patrimonio inmaterial. El caso de la cocina peruana. Apuntes, 24 (2), 196-207. Recuperado de https://revistas.javeriana.edu.co/index.php/revApuntesArq/article/view/8873 [1601-2020]

Mascarenhas, R. G. T. y Gândara, J. M. (2010). Producción y transformación territorial. La gastronomía como atractivo turístico. Estudios y Perspectivas En Turismo, 19 (5), 776-791. Recuperado de https://dialnet.unirioja.es/servlet/articulo?codigo=3352414> [24-11-2020]

Medina, F. X. (2017). Reflexiones sobre el patrimonio y la alimentación desde las perspectivas cultural y turística. Anales de Antropología, 51(2), 106-113. https://doi.org/10.1016/j.antro.2017.02.001

Millán Vázquez de la Torre, G., Hernández Rojas, R. y Navajas Romero, V. (2016). The study of Gastronomic Tourism in Córdoba and the asociation of the cuisine. An econometric analysis. Tourism and Hospitality Management, 22(2), 173191. https://doi.org/10.20867/thm.22.2.7

Ministerio de Cultura y Patrimonio. (2013). Guía de Huecas en ciudades patrimoniales. Nuestras Huecas para chuparse los dedos. Quito: Ministerio de Cultura y Patrimonio.

MINTUR (Ministerio de Turismo) (2018a).Turistas nacionales y extranjeros de la provincia de Pichincha. Quito: Ministerio de Turismo.

MINTUR (Ministerio de Turismo) (2018b). Reglamento turístico de alimentos y bebidas reconoce siete características. Quito. Recuperado de https://www.turismo.gob.ec/reglamento-turistico-de-alimentos-y-bebidas-reconoce-siete-categorias/ [16-02-2020]

MINTUR (Ministerio de Turismo) (2018c). Mapa Gastronómico del Ecuador. Quito: EDITOGRAN.

MINTUR (Ministerio de Turismo) (2020). Servicios turísticos del cantón Quito, Base de datos. Quito. Recuperado de https://servicios.turismo.gob.ec/index.php/turismo-cifras/2018-09-18-21-11-17/establecimientos-registrados [08-062020]

Montanari, A. y Staniscia, B. (2009). Culinary Tourism as a Tool for Regional Re-equilibrium. European Planning Studies, 17, 1463- 1483. https://doi.org/10.1080/09654310903141656

Monteros, A. (2016). Rendimientos de la papa en el Ecuador, Segundo ciclo 2015. Recuperado de https://fliphtml5.com/ijia/ psqo/basic> [30-09-2019]

Murra, J. (1997). La papa, el maíz y los ritos del Tawantinsuyo. En M. V. Rueda y S. E. Moreno Yánez (Eds.) Cosmos, hombre y sacralidad. Lecturas dirigidas de antropología religiosa (pp.181-193). Quito: Abya-Yala.

Pazos-Barrera, J. (2010). El Sabor de la Memoria. Quito: Fonsal. 
Poulain, J.P (2019). Sociologías de la alimentación, los comensales y el espacio social alimentario. Barcelona:UOC.

Prats, LI. (2011). La viabilidad turística del patrimonio. PASOS Revista de Turismo y Patrimonio Cultural, 9(2), 249-264. https: //doi.org/10.25145/j.pasos.2011.09.023

Pumisacho, M. (2011). Producción orgánica de la papa. En M. B. Suquilanda Valdivieso (Eds) Producción orgánica de cultivos andinos (pp: 13-42). Quito: Publiasesores.

Quito Turismo (2011). Experimenta Quito, guía turística oficial. Quito Turismo. Recupeado de https://issuu.com/quito_turismo/docs/experimenta_gu_a_tur_stica_oficia> [15-04-2020]

Quito Turismo (2019). Quito en cifras. Recuperado de https://www.quito-turismo.gob.ec/estadisticas/datos-turisticos-principales/category/82-quito-en-cifras> [14-04-2020]

Quito Turismo (2020). Sistema Institucional de Indicadores turísticos. Recuperado de http://quito-turismo.gob.ec/ [08-062020]

Ramón, P., Alarcón, T., Guerrero, K. y Vivero, A. (2018). Estrategia Agroalimentaria de Quito. In Pacto Agroalmentario de Quito, Alcaldía de Quito. Recuperado de http://gobiernoabierto.quito.gob.ec/wp-content/uploads/documentos/sistemaagro/documentos/Estrategia.pdf [29-10-2019]

Renting, H., Marsden, T. y Banks, J. (2003). Understanding Alternative Food Networks: Exploring the role of short food supply chains in rural development. Environment and Planning A, 35, 393-411. https://doi.org/10.1068/a3510

Romero, J. (2018). La gastronomía como atractivo turístico primario en el centro histórico de Quito. INNOVA Research Journal, 3(11), 194-203. https://doi.org/10.33890/innova.v3.n11.2018.813

Sistema de Información Pública y Agropecuaria (SIPA) (2018). Cifras Agropecuarias. In Ministerio de Agricultura y Ganadería. Quito. Recuperado de http://sipa.agricultura.gob.ec/index.php/cifras-agroproductivas [15-02-2020]

Stake, R. (2000). Case Studies. En N. Denzin. y Y. Lincoln (Eds.), Handbook of Qualitative Research (pp. 435-454). London: Sage Publications.

Thomé-Ortiz, H. (2015) Turismo agroalimentario y nuevos metabolismos sociales de productos locales. Revista Mexicana de Ciencias Agrícolas, 6 (6),1373-1386. https://doi.org/10.29312/remexca.v6i6.583

Thomé-Ortiz, H. (2018). Heritage cuisine and identity: free time and its relation to the social reproduction of local food. Journal of Heritage Tourism, 13(2), 104-114. https://doi.org/10.1080/1743873X.2017.1343336

Thomé-Ortiz, H., Vizcarra Bordi, I., Chávez-Mejía, C. y Herrera-Tapia, F. (2015). Turismo agroalimentario en el estado de México. Nuevos escenarios de investigación y acción en el medio rural. En Chávez, C. y Herrera, F. (Eds.) Procesos sociales en el medio rural. Acercamientos teóricos y experiencias de investigación (pp.159-194). México: Universidad Autónoma del Estado de México.

Torres, E. (2004). Del turismo en la política económica a la política económica del turismo. Quaderns de Política Económica, 7, 49-71. Recuperado de https://www.uv.es/ qpe/revista/num7/torres7.pdf [09-06-2020]

Troncoso, C. A. y Arzeno, M. B. (2019). Turismo, gastronomía y producción agraria en la provincia de Jujuy (Argentina): actores, dinámicas y transformaciones asociadas a la valorización de productos tradicionales. Investigaciones Turísticas, 18, 169-192. https://dx.doi.org/10.14198/INTURI2019.18.08

Trubek, A. (2008). The Taste of Place: A Cultural Journey into Terroir. Los Ángeles: University of California Press.

Unigarro, C. (2010). Patrimonio cultural alimentario. Quito: Ministerio de Cultura del Ecuador.

Unigarro, C., Terán, S., Pacheco, M., Guerrón, A. M. y Anda, S. (2014). De la chacra al fogón. Quito: Digital Center.

Vásquez-Medina, J. A. (2016). Cocina, nostalgia y etnicidad en restaurantes mexicanos de Estados Unidos. Barcelona: UOC.

Yurtseven, H.R, y Kaya O. (2011). Local food in local menus: The case of Gokceada. Tourismos: an international multidisciplinary journal of tourism, 6, 263-275. Recuperado de http://www.chios.aegean.gr/tourism/VOLUME_6_No2_art15. pdf [25-02-2020] 


\section{ANEXO 1}

\section{GUIÓN DE ENTREVISTA SEMIESTRUCTURADA A REPRESENTANTES DE ESTABLECIMIENTOS ALIMENTA- RIOS DEL CENTRO HISTÓRICO DE QUITO}

1. ¿Cuánto tiempo tiene con el establecimiento?; ¿Lo heredó?; ¿Por cuántas generaciones ha permanecido en su familia?

2. ¿Qué tipo de comida comúnmente ofrece en su establecimiento? Mencione los platos.

3. ¿Qué platos tradicionales ofrece en su establecimiento?

4. ¿Qué plato es el más solicitado en este establecimiento?

5. ¿Dónde compra los productos para la elaboración de alimentos?

6. ¿Compraría los productos alimentarios directamente a un productor del cantón Quito?; ¿Por qué?; ¿Qué beneficios y dificultades percibe de comprar a un pequeño productor local o a un distribuidor de gran escala?

7. ¿Quiénes son los principales consumidores de estos platos tradicionales?

8. ¿Considera usted algún plato tradicional como representativo del cantón Quito? ¿Por qué es representativo?

9. ¿Cree usted que hay un plato representativo del cantón Quito para el público nacional y local? ¿Cree usted que hay plato representativo del cantón Quito para el público extranjero? ¿Cuál sería? ¿Por qué es representativo para estos públicos?

10. ¿Cómo cree que se podría pocisionar un plato tradicional como representativo del cantón Quito?

11. ¿Cómo podría indetificarse la calidad de un alimento tradicional? ¿Cómo garantiza la calidad de los productos de ofrece?

12. ¿Cúales son los retos y oportunidades que representa la ubicación del centro histórico para la venta de alimentos tradicionales?

13. ¿Hay algo que desee agregar que no le haya preguntado? 


\section{ANEXO 2 \\ ENCUESTA SOBRE ALIMENTOS IDENTITARIOS DEL ECUADOR}

Edad: Dirección: Fecha: Nivel de escolaridad: Ocupación:

1. ¿Qué alimentos cree usted son la base de su dieta alimentaria de la comida ecuatoriana?

2. ¿De los alimentos que mencionó antes, ¿Conoce dónde fueron cultivados?

SI NO

3. (Si respondió SI a la anterior pregunta) ¿Diga el nombre donde fueron cultivados los alimentos que son la base de su dieta alimentaria

4. ¿Qué alimentos cree usted proporcionan identidad a su región de procedencia?

\begin{tabular}{|l|}
\hline A. papa \\
\hline B. plátano \\
\hline C. yuca \\
\hline D. melloco \\
\hline E. quinua \\
\hline F. maíz \\
\hline G. cerdo \\
\hline H. cuy \\
\hline I. chochos \\
\hline J. achiote \\
\hline K. coco \\
\hline L. cebada \\
\hline M. Otro:Cuál?: \\
\hline
\end{tabular}

5. ¿Qué alimentos cree usted proporcionan identidad a la nación ecuatoriana?

\begin{tabular}{|l|}
\hline A. papa \\
\hline B. plátano \\
\hline C. yuca \\
\hline D. melloco \\
\hline E. quinua \\
\hline F. maíz \\
\hline G. cerdo \\
\hline H. cuy \\
\hline I. chochos \\
\hline J. achiote \\
\hline K. coco \\
\hline L. cebada \\
\hline M. Otro:Cuál?: \\
\hline
\end{tabular}


6. ¿Qué lugares o personas cree que se relacionan con los alimentos que mencionó antes?

\begin{tabular}{|l|}
\hline A. Fiestas tradicionales \\
\hline B. Restaurantes \\
\hline C. Familias \\
\hline D. Personas de la tercera edad \\
\hline E. Dietas \\
\hline F. Agricultores y Ganaderos \\
\hline
\end{tabular}

6. ¿Qué alimento, cuando usted saborea un plato de comida ecuatoriano de su región, no puede faltar?

7. ¿Cuál es su lugar de procedencia?

8. ¿Quéplatodecomidatradicionalidentificaasulugardeprocedencia?

9. ¿Le gustaría comer un plato con alimentos identitarios en una visita turística al cantón Quito? SI NO

10. ¿Normalmente cuándo visita el cantón Quito, ¿cuál es la razón de su viaje?

$\begin{array}{ll}\text { Visita a familiares y/o amigos___ Comer } \\ \text { Fiestas del lugar } & \text { Cultura } \\ \text { Ecoturismo/aventura } & \text { Negocios } \\ \text { Congreso/Exposición } & \text { Salud } \\ \text { Estudios/Académico } & \text { Compras } \\ \text { Religión/Peregrinación__ Otra ¿Cuál? } & \text { OtCanso }\end{array}$

11. Señale las 5 principales actividades que realiza durante su estancia en ese lugar:

Pasear por el parque/iglesia

Visitar centros recreativos

Compra productos de la región

Comer en restaurantes/mercado

Asistir a fiestas del lugar

Visitar haciendas/fincas

Visitar áreas protegidas

Visitar un río/cascada

Admirar el paisaje

Observación de flora y fauna

Descansar

Caminata

Fotografía

Deportes de aventura, cuales:

Otras actividades ¿cuáles? 
12. ¿Qué actividad relacionada con el alimento, además de las mencionadas, le gustaría conocer o hacer en el cantón Quito?

13. ¿Cuando va al cantón Quito con quién realiza su viaje ?

14. ¿Cuantos días le gustaría hacer una ruta turística donde la principal razón de la visita es un alimento?

\begin{tabular}{|l|}
\hline A. 1 día \\
\hline B. 2 días \\
\hline C. 3 días \\
\hline D. 4 o más días \\
\hline
\end{tabular}

15. ¿Le gustaría visitar granjas de pequeños productores como parte de la experiencia en el conocimiento y degustación de la comida tradicional?

SI NO

16. ¿Le gustaría aprender cómo se prepara la comida tradicional cuando visite el cantón Quito, como parte de la experiencia en el conocimiento y degustación de la comida tradicional?

SI NO

17. ¿Aproximadamente cuál es su ingreso familiar mensual? dólares

18. ¿Cuál es su gasto diario en el cantón Quito de usted y sus acompañantes?

Alojamiento

Alimentos

Compras y artesanías talvez

Otros gastos

Total

19. ¿Cuánto gasta de manera total en un viaje al cantón Quito? (Considere desde la salida hasta el regreso a su lugar de origen, incluyendo usted y sus acompañantes) 